\title{
Small Heat Shock Proteins, Amyloid Fibrils, and Nicotine Stimulate a Common Immune Suppressive Pathway with Implications for Future Therapies
}

\author{
Jonathan B. Rothbard, ${ }^{1}$ Michael P. Kurnellas, ${ }^{2}$ Shalina S. Ousman, ${ }^{3}$ Sara Brownell, ${ }^{4}$ \\ Jesse J. Rothbard, ${ }^{1}$ and Lawrence Steinman ${ }^{1}$ \\ ${ }^{1}$ Department of Neurology, Stanford University School of Medicine, Stanford, California 94305-5316 \\ ${ }^{2}$ Alector, South San Francisco, California 94080 \\ ${ }^{3}$ Department of Clinical Neurosciences, University of Calgary, Alberta T2N 1N4, Canada \\ ${ }^{4}$ School of Life Sciences, Arizona State University, Tempe, Arizona 85281 \\ Correspondence: rothbardj@gmail.com; steiny@stanford.edu
}

The $\alpha 7$ nicotinic acetylcholine receptor $(\alpha 7 \mathrm{nAChR})$ is central to the anti-inflammatory function of the vagus nerve in a physiological mechanism termed the inflammatory reflex. Studies on the inflammatory reflex have been instrumental for the current development of the field of bioelectronic medicine. An independent investigation of the biological role of $\alpha \mathrm{B}$-crystallin (HspB5), the most abundant gene transcript present in active multiple sclerosis lesions in human brains, also led to $\alpha 7 \mathrm{nAChR}$. Induction of experimental autoimmune encephalomyelitis (EAE) in $\mathrm{HspB}^{-/-}$mice results in greater paralytic signs, increased levels of proinflammatory cytokines, and T-lymphocyte activation relative to wild-type animals. Administration of HspB5 was therapeutic in animal models of multiple sclerosis, retinal and cardiac ischemia, and stroke. Structure-activity studies established that residues 73-92 were as potent as the parent protein, but only when it formed amyloid fibrils. Amyloid fibrils and small heat shock proteins (sHsps) selectively bound $\alpha 7 \mathrm{nAChR}$ on peritoneal macrophages (MФs) and B lymphocytes, converting the $M \Phi$ s to an immune suppressive phenotype and mobilizing the migration of both cell types from the peritoneum to secondary lymph organs. Here, we review multiple aspects of this work, which may be of interest for developing future therapeutic approaches for multiple sclerosis and other disorders.

$\mathrm{T}^{\mathrm{h}}$ his review represents close to 20 years of research from the initial realization that small heat shock proteins (sHsps) are prominent in the lesions in the brains of patients with multiple sclerosis to the realization that they, and amyloid fibrils, bind $\alpha 7$ nicotinic acetylcholine receptor
( $\alpha 7 \mathrm{nAChR})$ on the surface of macrophages (MФs) and B lymphocytes. This binding triggers stimulation of an inherent immune suppressive program. Previously, the anti-inflammatory role of the $\alpha 7 \mathrm{nAChR}$ has been studied in the context of the vagus nerve-mediated in-

Editors: Valentin A. Pavlov and Kevin J. Tracey

Additional Perspectives on Bioelectronic Medicine available at www.perspectivesinmedicine.org

Copyright (C) 2019 Cold Spring Harbor Laboratory Press; all rights reserved; doi: 10.1101/cshperspect.a034223

Cite this article as Cold Spring Harb Perspect Med 2019;9:a034223 
J.B. Rothbard et al.

flammatory reflex, a physiological mechanism that regulates proinflammatory cytokine release and inflammation in several inflammatory conditions (Pavlov et al. 2007; Pavlov and Tracey 2012, 2017). The inflammatory reflex can be potentiated by bioelectronic stimulation of the vagus nerve. Hence, these findings highlight an important and clinically relevant link to the inflammatory reflex and the anti-inflammatory function of the vagus nerve. Below, we provide a detailed overview of these relevant studies.

\section{DISCOVERY OF THE IMPORTANCE OF SMALL HEAT SHOCK PROTEINS IN EAE}

Investigation of the composition of plaques in the brains of patients with multiple sclerosis revealed that an $\mathrm{sHsp}, \alpha \mathrm{B}$-crystallin ( $\mathrm{HspB} 5$ ), is the most abundant gene transcript (Chabas et al. 2001) and expressed protein (Ousman et al. 2007; Han et al. 2008). The clinical significance of this observation was supported by the absence of the transcript in normal brain tissue (Chabas et al. 2001) and HspB5 ${ }^{-/-}$mice showing significantly greater paralytic signs when experimental autoimmune encephalomyelitis (EAE) was in- duced (Fig. 1) (Ousman et al. 2007). Compared with wild-type animals, myelin oligodendrocyte glycoprotein-immunized $\mathrm{HspB}^{-1-}$ mice display higher T-cell proliferation, increased secretion of interleukin (IL)-2, interferon (IFN) $-\gamma$, tumor necrosis factor (TNF)- $\alpha$, IL-1, IL-12 p40, IL-17, and more intense central nervous system (CNS) inflammation (Fig. 1A-C). Astrocytes from knockout animals also show greater amounts of cleaved caspase- 3 and increased TUNEL staining, indicating the presence HspB5 reduces apoptosis. Remarkably, even though HspB5 lacks a leader sequence and most of its documented activities were intracellular, Ousman and colleagues (2007) showed that intravenous or intraperitoneal injection of the protein was therapeutic in animals with EAE.

Initial mechanistic studies established that HspB5 inhibited the nuclear factor (NF)- $\mathrm{B}$ pathway (Ousman et al. 2007). In vitro exposure of astrocytes from $\mathrm{HspB} 5^{-1-}$ mice to TNF- $\alpha$ resulted in increased expression of NF- $\kappa \mathrm{B}$ p 65 and NF- $\kappa$ B p105/p50 with reduction of $I \kappa B-\alpha$. Similar stimulation of wild-type astrocytes led to an increase in $I \kappa B-\alpha$ without induction of $\mathrm{NF}-\kappa \mathrm{B}$ p50. HspB5 was shown to prevent cell

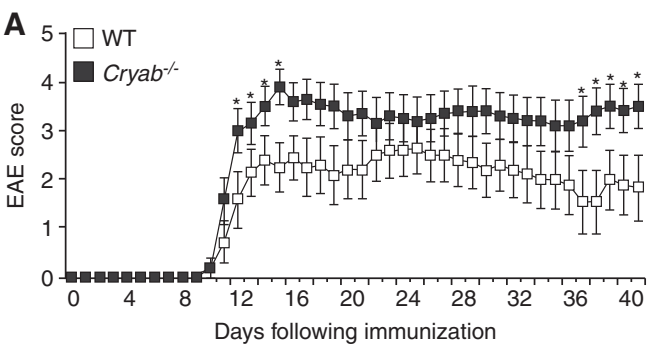

C
B

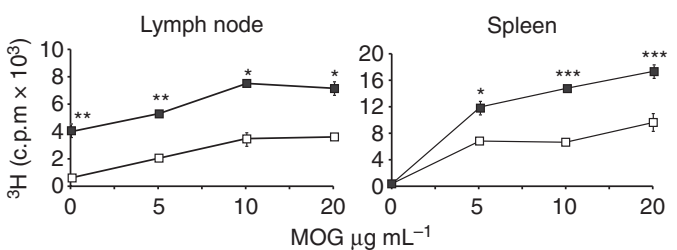

Spleen

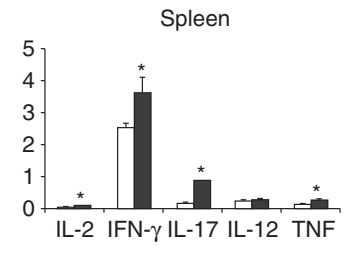

Figure 1. Induction of experimental autoimmune encephalomyelitis (EAE). Induction of EAE in $\mathrm{HspB} 5^{-/-}$mice results in more severe paralytic signs $(A)$, greater T-lymphocyte activation $(B)$, and increased levels of proinflammatory cytokines $(C)$, relative to wild-type (WT) animals. Representatives from four EAE experiments show mean \pm SEM clinical scores of WT and $\mathrm{HspB}^{-/-}$mice $(A)\left({ }^{*} P<0.05\right.$ Mann-Whitney; $P=0.0008$ linear regression days $9-15 ; n=10$ mice per group); and proliferation rate $(B)$ and cytokine production $(C)$ from WT and $\mathrm{HspB5}^{-/-}$(mean $\pm \mathrm{SEM} ;{ }^{*} P<0.05,{ }^{* *} P<0.02,{ }^{* *} P<0.005$, Student's $t$-test). MOG, Myelin oligodendrocyte glycoprotein; IL, interleukin; IFN, interferon; TNF, tumor necrosis factor. 
death of astrocytes by inhibiting caspase-3 activation and suppressing the inflammatory role of $\mathrm{NF}-\kappa \mathrm{B}$ in astrocytes during demyelinating disease. These findings were the first indication that HspB5 stimulated an immune suppressive response of significant magnitude to be therapeutic in an animal model of multiple sclerosis.

\section{THERAPEUTIC EFFICACY OF sHsps IN ANIMAL MODELS OF INFLAMMATION}

Retinal and Cardiac Ischemia

To determine whether HspB5 was effective in reducing inflammation in other animal models, the protein was administered to murine models of retinal and cardiac ischemia. In the former case, both acute (daily for 3 days) or long-term (every other day for 3 weeks) administration of HspB5 was beneficial in anterior ischemic optic neuropathy. The disease was induced in adult mice and the therapeutic benefits were analyzed using histological and serial intracranial flash, visual-evoked potential recordings (PangratzFuehrer et al. 2011). Overt swelling and microglial and astrocytic activation were reduced after 3 days of daily intravenous or intravitreal injections of HspB5. Visual-evoked potential latency was apparent after 3 weeks, without improving amplitude. The latency acceleration correlated with the complete rescue of the optic nerve oligodendrocytes, which are essential for remyelination.

The protective effects of exogenous HspB5 on myocardial function after ischemia-reperfusion injury were analyzed in a second study (Velotta et al. 2011). The left anterior descending artery was occluded for $30 \mathrm{~min}$ in C57BL/6 mice and either HspB5 (50 $\mu \mathrm{g}$ ) or phosphate-buffered saline (PBS) were injected in the intramyocardial medial and lateral peri-infarct zone 15 min before reperfusion. HspB5 was administered by intraperitoneal injection every other day for 40 days and magnetic resonance imaging was performed on day 40 to measure left ventricular ejection fraction. HspB5-treated mice had a 1.8-fold increase in left ventricular ejection fraction versus control mice $(27 \% \pm 6 \%$ vs. $15 \% \pm 4 \%$ [mean $\pm \mathrm{SD}$ ], $P<0.005)$, revealing that exogenous HspB5 administration significantly improved cardiac function after ischemia-reperfusion injury, in vivo.

\section{Stroke}

The HspB5 knockout mouse also was used to show the importance of the Hsp in cerebral ischemia (Arac et al. 2011). After $30 \mathrm{~min}$ of middle cerebral artery occlusion, $\mathrm{HspB} 5^{-/-}$ mice showed significantly larger lesion sizes at 2 days than their wild-type counterparts (Fig. 2A). The difference was even more apparent after 7 days (Fig. 2B), indicating the deficiency of HspB5 affected both the early and delayed phases of ischemic damage. The HspB5 $5^{-1-}$ mice showed significantly worse scores at both 2-day and 7-day time points compared with wild-type controls when the functional outcome of the ischemia was assessed (Fig. 2C). Analysis of the cellular infiltrate into the brain of the knockout animals revealed granulocyte and macrophage migration preceded the presence of T lymphocytes, with higher numbers of all populations in the knockout animal.

The beneficial effects of HspB5 administration were observed when wild-type mice were treated with intraperitoneal injections of either PBS or HspB5 $1 \mathrm{~h}$ before, $12 \mathrm{~h}$ after the stroke onset, and daily for 7 days. The lesion sizes in both groups of animals were equivalent at early time points. However, after $24 \mathrm{~h}$ and more obviously after 7 days, the lesion sizes were significantly reduced in the HspB5-treated animals compared with the PBS-treated group. In a second experiment, the initial treatment was postponed until $12 \mathrm{~h}$ after the stroke onset, with daily injections for 7 additional days (Fig. 2D). This clinically relevant protocol also conferred neuroprotection in the HspB5-treated group. Currently, in the clinic, tissue plasminogen activator is the only treatment option for stroke victims and has to be administered within $4.5 \mathrm{~h}$ after symptom onset, which severely limits its use. The result showing the administration of HspB5 was effective at reducing both stroke volume and inflammatory cytokines even $12 \mathrm{~h}$ after experimental stroke is clinically important. 
J.B. Rothbard et al.

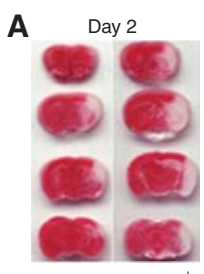

Wild type $\mathrm{HspB}^{-1}$
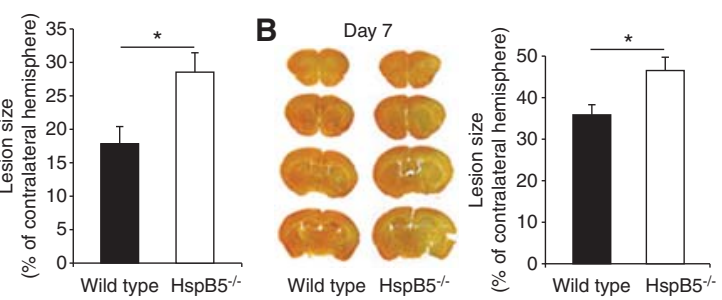

C

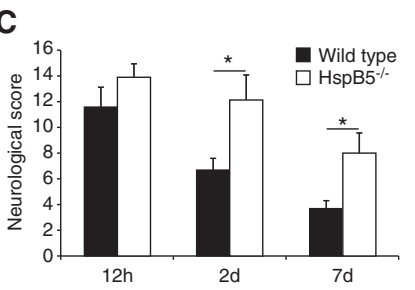

D
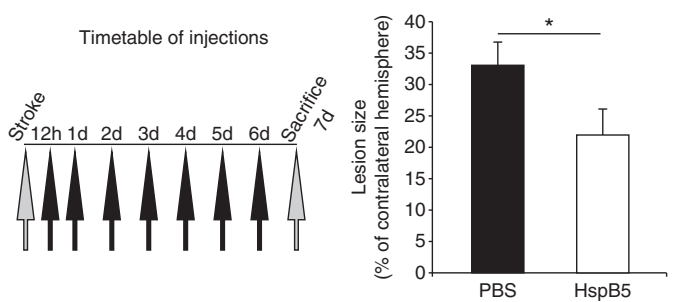

Figure 2. Stroke induction in $\mathrm{HspB}^{-/-}$mice results in larger lesions and worse neurological scores compared with wild-type animals. ( $A$ ) Representative images of triphenyltetrazolium chloride (TTC)-stained brain sections of wild-type and $\mathrm{HspB}^{-1-}$ mice and quantification of lesion sizes 2 days after stroke ( $n=10$ per group). (B) Representative images of silver-stained brain sections and quantification of lesion sizes 7 days after stroke. (C) Quantification of 28-point neurological scoring in wild-type and $\mathrm{HspB}^{-/-}$mice at 12 hours (h), 2 days (d), and 7 days after stroke. For $B$ and $C, n=10$ and 7 for wild-type and $\mathrm{HspB}^{-/-}$groups, respectively. (D) Timetable of treatment protocol and quantitation of lesion sizes in phosphate-buffered saline (PBS) and HspB5-treated wild-type mice 7 days after stroke as assessed by silver stain; $n=14$ and 15 for PBS and HspB5treated groups, respectively. ${ }^{*} P<0.05$, Student's $t$-test.

Collectively, the beneficial results seen in animal models of EAE, ischemia, and stroke show the anti-inflammatory effects induced by HspB5 are the reduction of secretion of proinflammatory cytokines, inhibition of T-cell proliferation, and limiting apoptosis.

\section{STRUCTURE-ACTIVITY RELATIONSHIPS IN sHsps}

sHsps are a family of structurally diverse molecule chaperones that aggregate to form a spectrum of oligomers, which bind partially denatured regions of proteins and prevent their aggregation (Kappe et al. 2002, 2003; Haslbeck et al. 2005). In contrast with large Hsps, sHsps do not catalyze the ATP-driven refolding of denatured proteins, but rather simply prevent their aggregation. By limiting the concentration of aggregated proteins, they minimize amyloid formation and their consequent cytotoxicity (Narberhaus 2002). In addition to their chaperone function, several groups have established specific interactions between human sHsps and cytosolic proteins such as $\mathrm{p} 53$ and Bax to inhibit apoptosis (Kamradt et al. 2001, 2005; Liu et al. 2004, 2007; Mao et al. 2004).

The structures of wheat, pea, tapeworm, Caenorhabditis elegans, mycobacteria, and human sHsps have been solved revealing a closely related family of proteins, which differ in their dynamic quaternary structure with different stoichiometries but share a common unit cell. The shared structure is a dimer with each subunit folding into a conserved $\beta$-barrel with amino- and carboxyl-terminal residues lacking defined structure (Kim et al. 1998a,b; van Montfort et al. 2001; Haslbeck et al. 2004; Kennaway et al. 2005; Laganowsky et al. 2010, 2012). Even though the extensions are not constrained in a defined secondary structure, they are integral in the formation and stabilization of dimers and aggregates of the dimers (Pasta et al. 2004; Hochberg et al. 2018). There are 10 members of the sHsp family in man, sHspB1-10, which differ in their tissue expression and their ability to respond to environmental insult. The majority of the proteins are constitutive, with 
only three (HspB1, B5, and B8) being induced by stress.

To determine whether other human sHsps shared the therapeutic activity of HspB5, seven human family members (Hsp1-4, 6-8), a mutant of HspB5, G120, known for reduced chaperone activity, and a mycobacterial sHsp (acr-1) were expressed in bacteria and purified (Kurnellas et al. 2012). Each of the recombinant proteins, with the exception of HspB5 G120, efficiently inhibited aggregation of denatured insulin, and therefore was a functional chaperone. HspB5 G120 did inhibit aggregation at higher concentrations than the parent structure, which is an important detail because all nine sHsps were therapeutic in mice with EAE when injected intraperitoneally daily beginning with the appearance of paralytic signs. The common therapeutic activity was puzzling, because the HspB5 mutant, G120, and the mycobacterial sHsp, acr-1, were included in the experiment with the belief they would be ineffective. A detailed dose-response therapeutic experiment was not performed, but the shared therapeutic activities of these family members indicated there was either a critical shared conformation, a shared sequence, or a combination of the two.

\section{CORRELATION OF THERAPEUTIC ACTIVITY WITH AMYLOID FIBRIL FORMATION}

The possibility of a shared sequence as the explanation for the similar therapeutic activity of the family of sHsps was pursued by analyzing linear regions within HspB5. Residues 73-92 in both HspB4 and HspB5 had been shown to be a functional chaperone (Narberhaus 2002), but this region became far more interesting based on a critical finding by Tanaka and colleagues (2008). They showed that the chaperone activity of residues 73-92 of HspB4 correlated with its ability to form amyloid fibrils. This observation both explained how a relatively short peptide could show equivalent biologic function as a fully folded protein, and that amyloid fibrils could be molecular chaperones. This last statement is puzzling because, historically, chaperones were thought to prevent amyloid fibril formation. If anything, amyloid fibrils were be-
Stimulation of an Immune Suppressive Pathway

lieved to catalyze their own formation, so-called seeding, and not act as inhibitors. However, the literature on heterologous interactions between different amyloidogenic proteins is nonexistent.

Consistent with Tanaka's report, amyloid fibrils were found in solutions of residues 7392 from HspB1, B4, and B5 both by thioflavin T binding and atomic force microscopy (Kurnellas et al. 2012). When tested as therapeutics for EAE, residues 73-92 of HspB1, B4, and B5 were equally effective in reducing the paralytic signs of EAE, limiting the secretion of the proinflammatory cytokines, IL-6, TNF- $\alpha$, IL- $1 \beta$, and IL-2, and inhibiting of T-cell proliferation (Ousman et al. 2007), showing a common immune suppressive activity with the full-length proteins (Kurnellas et al. 2012). Point mutations within the peptides, which disrupt amyloid formation, eliminated chaperone function, and all therapeutic effects in the EAE animal model. Collectively, these experiments showed a unique and unexpected correlation between the chaperone function, amyloid formation, and immune suppressive activity (Kurnellas et al. 2012).

A central feature of amyloid fibrils is an Xray diffraction pattern consistent with an extended $\beta$-pleated sheet. However, the limited solubility and polydispersity of the associated nonamyloid portions protein fibrils has limited their crystallographic solutions. An alternative strategy taken by Eisenberg and colleagues has been to form amyloid fibrils composed of peptides as short as five and six amino acids (Balbirnie et al. 2001; Nelson et al. 2005; Sawaya et al. 2007). When dissolved in physiological buffers, the peptides self-assemble into extended pairs of $\beta$-pleated sheets. As with protein amyloids, the dominant structural element is a cross $\beta$-spine, but fibrils formed from these relatively short peptides show greater structural simplicity, relative homogeneity, lack of cytotoxicity, and increased solubility in physiological buffers, thus rendering them more suitable for understanding how fibril structure impacts physiology than protein amyloids. In addition, several groups have devised algorithms to predict amyloidforming regions based on $\beta$-sheet propensity and the capacity to form complementary segments capable of close packing characteristics 
J.B. Rothbard et al.

of the zipper-like configuration observed in the crystal structures (Thompson et al. 2006; Goldschmidt et al. 2010).

Within the 73-92 region of HspB5, the algorithm developed by Goldschmidt and Eisenberg (Goldschmidt et al. 2010) predicted two amyloidogenic regions within the peptide, residues 76-81 and 89-94. Intraperitoneal injection of amyloid fibrils composed of these peptides modulated the paralytic clinical signs of EAE in a dose-dependent fashion and reduced serological levels of IL-6 (Fig. 3A). To establish further that any amyloid fibril was equally effective, 16 other hexamer sequences from A- $\beta$ A4, Tau, insulin $A$ and $B$ chains, serum amyloid $P$, amylin, apolipoprotein $\mathrm{E}$, and $\operatorname{IgK}$ were shown to reduce the paralytic signs of EAE and limit the production of proinflammatory cytokines (Fig.
3B-F) (Kurnellas et al. 2013). Amyloid formation appears to be central to the immune suppressive effects because there was significant amyloid content in the preparations of the full-length sHsps. Whether this was caused by the formation of amyloid fibrils or binding of amyloid fibrils, or a mixture of both is unknown, but the amyloidogenic character of sHsps appears to be central to their biological role. That amyloid-forming peptides are immunosuppressive and therapeutic is counterintuitive to the numerous publications emphasizing their correlation with inflammation. The type of inflammation, particularly in the CNS, described in this body of literature, is certainly unlike classic inflammation that comprises a basic medical school curriculum. In the presence of amyloid deposits, there is little evidence to support infil-
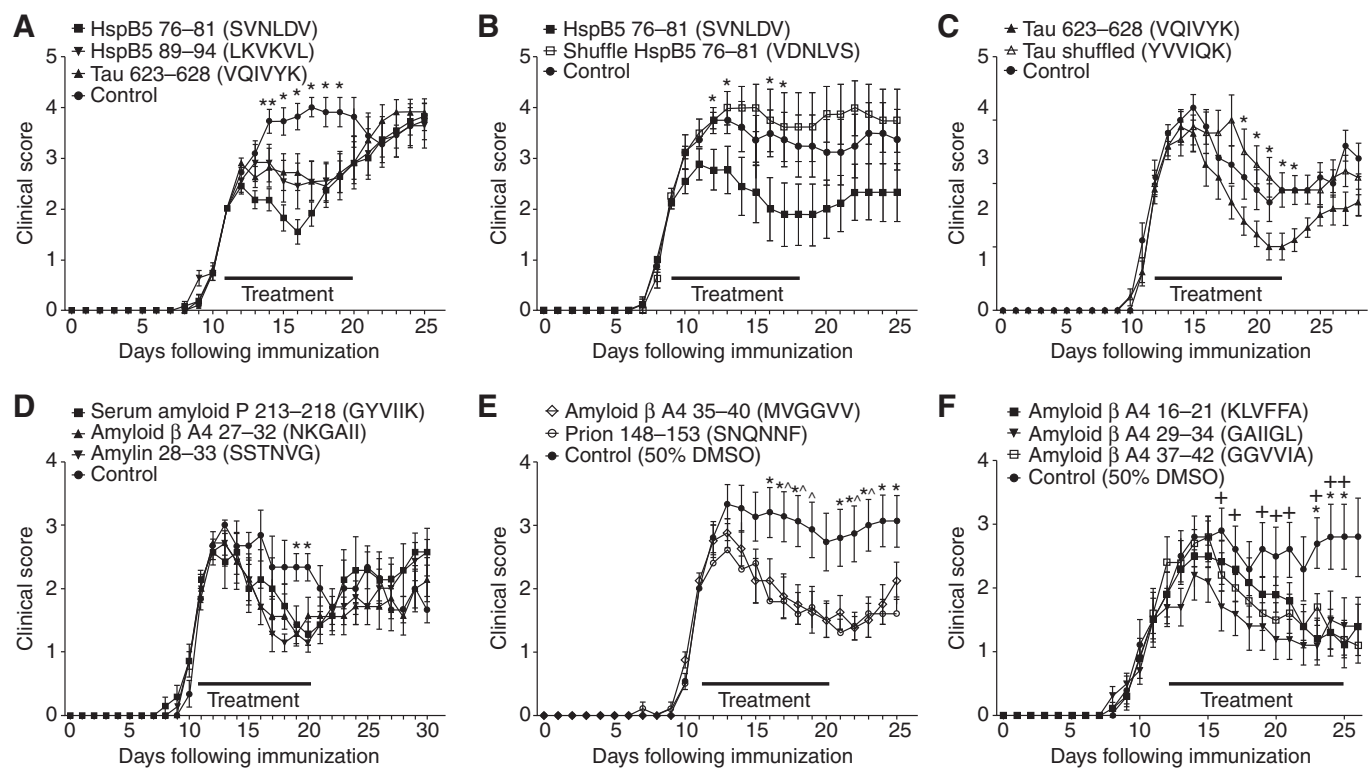

Figure 3. Reduction of paralytic symptoms in mice with experimental autoimmune encephalomyelitis (EAE) by injection of amyloidogenic hexapeptides. Groups of 10 mice were injected daily with $1 \mathrm{mg}$ of the listed peptides beginning at onset of hindlimb weakness. Phosphate-buffered saline (PBS) or PBS containing 50\% dimethyl sulfoxide (DMSO) was injected in control littermates. (A) Hexapeptides corresponding to residues 76-81 and 89-94 of HspB5, and 623-628 of Tau effectively reduced the paralytic signs and the signs of clinical disease of EAE. $(B, C)$ The shuffled analogs of HspB5 76-81 and Tau 623-628 were ineffective. $(D)$ Hexamers corresponding to serum amyloid P (SAP) 213-218, A 3 A4 27-32, and Amylin 28-33 were therapeutic. (E) Two poorly soluble peptides, prion $148-153$ and A $\beta$ A4 35-40, were therapeutic when administered in $50 \%$ DMSO. $(F)$ A $\beta$ A4 16-21, 29-34, and 37-42 were therapeutic when administered in 50\% DMSO. Bars represent the duration of the treatment. Values in graph represent means \pm SEM. ${ }^{*} P<0.05$ for all peptides, ${ }^{\wedge} P<0.05$ for MVGGVV, ${ }^{+} P<$ 0.05 for A $\beta$ A4 29-34 by the Mann-Whitney $U$-test. 
tration of monocytoid myeloid cells that is so very characteristic of classic inflammation.

Amyloid Fibrils Are Endocytosed by Peritoneal B Cells and Macrophages and Stimulate Their Migration to Secondary Lymph Organs

The principal cell populations in murine peritoneal cavities are large and small MФs, B-1a, B2, and $\mathrm{T}$ lymphocytes, and a small number of granulocytes. To explore the biological responses induced by the amyloid fibrils within this cell population, fibrils composed of fluorescently labeled Tau 623-628 were injected in the peritoneum of healthy, wild-type C57BL/6 mice (Kurnellas et al. 2015). Peritoneal cells were collected by lavage at various times between $10 \mathrm{~min}$ and $5 \mathrm{~h}$ after injection, stained with anti-CD19 and antiF4/80, and layered on polylysine-coated slides. Analysis of the uptake of the fluorescent fibrils using confocal microscopy revealed the fibrils were bound and endocytosed by both $\mathrm{B}$ cells $\left(\mathrm{CD} 19^{+}\right)$and $\mathrm{M \Phi s}\left(\mathrm{F} 4 / 80^{+}\right)$(Fig. 4). Within 10 min of the FITC-Tau injection $>70 \%$ of the B-1 and B-2 lymphocytes and large peritoneal MФs were FITC ${ }^{+}$(Fig. 4D). In contrast, T lymphocytes and mast cells were minimally stained, showing specific binding or uptake by B cells and MФs (Fig. 4). Five hours after injection of the fibrils, the majority of the CD $11 b^{\text {hi }}$ population were significantly reduced from $\sim 45 \%$ to $3 \%$ of total peritoneal cells, while most of the $\mathrm{B}-1 \mathrm{a}$ population disappeared, with the remaining cells being FITC-Tau negative. The majority of T lymphocytes and mast cells were unstained. Collectively, the flow cytometry studies revealed that the fibrils specifically bind B cells and MФs, and that the relative number of B-1a lymphocytes $\left(\mathrm{CD} 19^{\mathrm{hi}} \mathrm{CD} 5^{+}\right)$and the large peritoneal MФs $\left(C D 11 b^{\text {hi }}\right)$ was dramatically reduced $5 \mathrm{~h}$ after injection of the amyloid.

The loss of the cells in the peritoneum could have been due to the toxicity of the fibrils because the reduction of the specific cell populations, B lymphocytes, and MФs correlated with uptake. However, no cell death was observed when the peritoneal cells were cultured in vitro with the fluorescent amyloid. An alternative explanation was that the fibrils induced the migration of the two cell populations from the peritoneum, a known effect of injection of lipopolysaccharide (LPS). To determine whether this was the case, real-time measurement of bioluminescence was used to show that the amyloidogenic peptides induce the migration of both B-1a cells and MФs from the peritoneum. B-1a cells

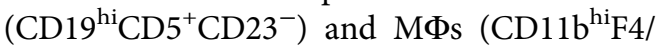
$80^{\mathrm{hi}}$ ) were sorted from peritoneal cells isolated from luciferase transgenic mice, C57BL/6 L2G85 $\left(\mathrm{H}-2^{\mathrm{d}}\right) \quad$ (B6.FVB-Ptprca Tg(CAG-luc,-GFP) L2G85Chco Thyla/J), which express the CATluc-eGFP, L2G85 transgene (Kurnellas et al. 2015). Purified B-1a cells were injected into the peritoneum of $\mathrm{C} 57 \mathrm{BL} / 6$ female albino mice, along with Tau 623-628 to activate the lymphocytes, and luciferin, to initiate the reaction necessary for the bioluminescence imaging. The mice were monitored by imaging to locate the luciferase positive cells. The initial luminescence was a diffuse pattern within the peritoneal cavity whose intensity reduced over time. Quantitation of the total number of photons per second in the abdominal region revealed a rapid, dose-dependent reduction of light emitted. In all animals, the size of the signal was proportional to the number of cells injected, but the rate of reduction or slope of the curve as a function of time was equivalent, consistent with the amyloid fibrils triggering egress of the B-1a cells from the peritoneum (Kurnellas et al. 2015).

$\mu \mathrm{MT}$ and IL-10 Knockout Mice Are Resistant to Therapy with Amyloid Fibrils

\section{Adoptive Transfer of B-1a Cells Restored Therapeutic Efficacy of Amyloidogenic Peptides in $\mu M T$ Animals}

The binding of fibrils to B lymphocytes and, in particular, B-1a cells in the peritoneum led to further study of this cell population. B-1a cells are characterized by the constitutive expression and secretion of relatively large amounts of IL10 (O'Garra and Howard 1992; O'Garra et al. 1992), which would be expected to reduce inflammation if the cells migrated to secondary lymph organs. To determine the importance of B lymphocytes in the mode of action of the amyloid fibrils, EAE was induced in $\mu \mathrm{MT}$ mice, 
J.B. Rothbard et al.
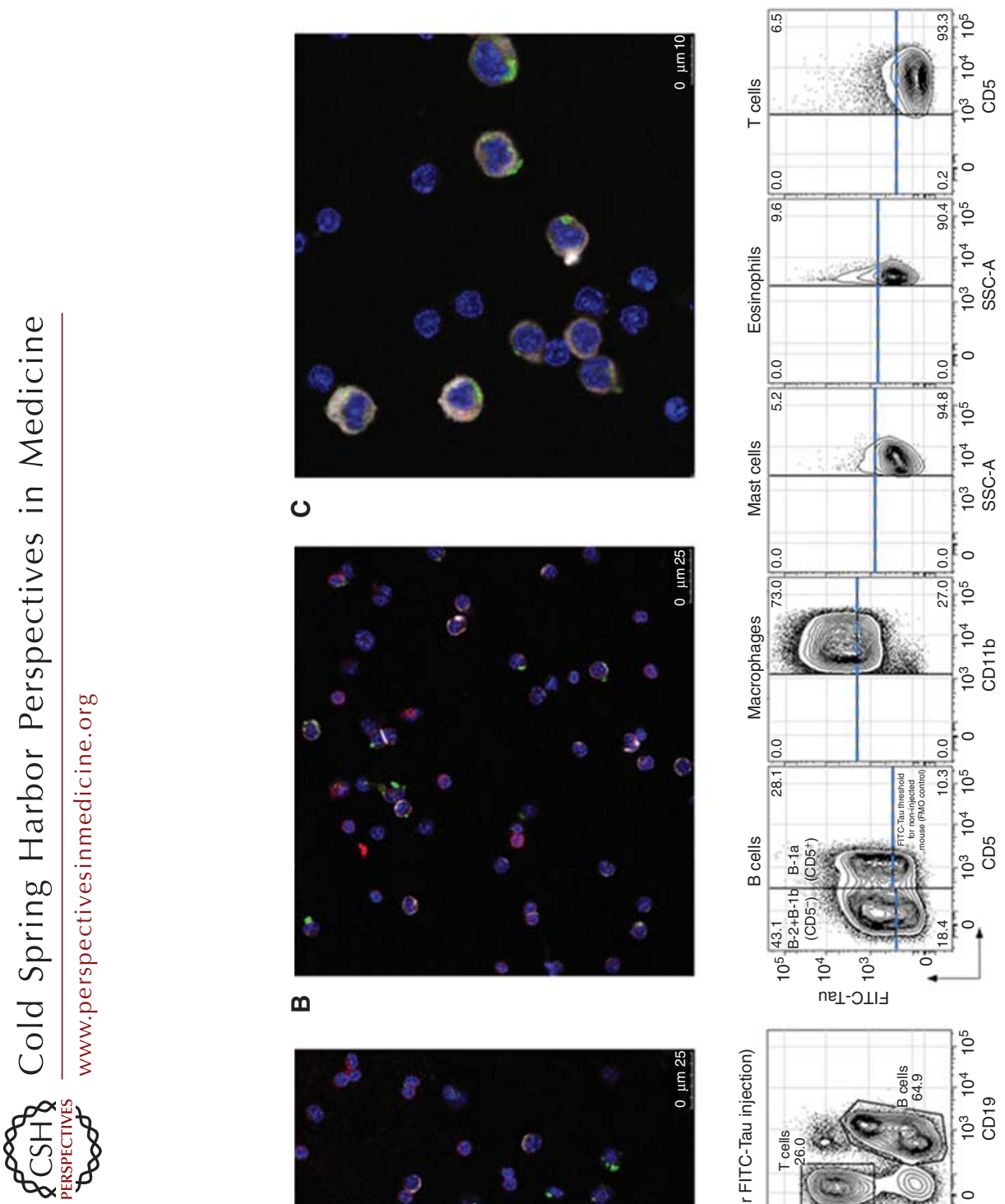

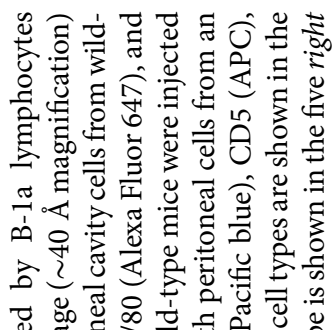

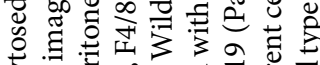

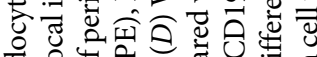

过

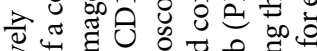

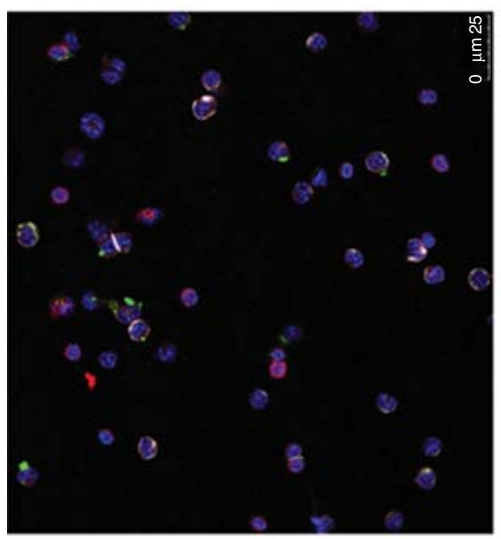

$\mathbf{m}$

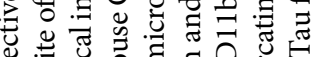

㻤

क :

ప

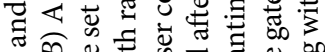

ची

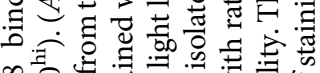

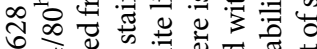

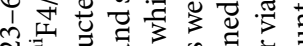

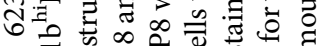

च $\bar{\nabla}$ तु क

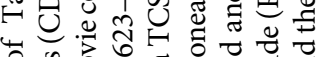

ช

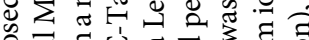

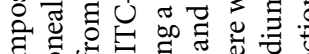

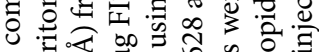

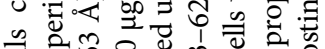

윰

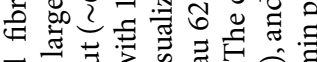

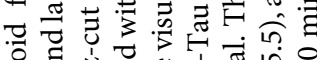

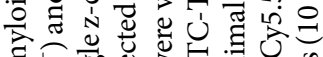

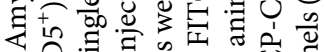

४⿻ी

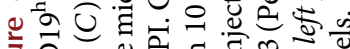

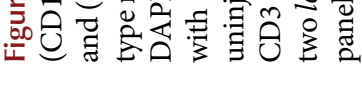

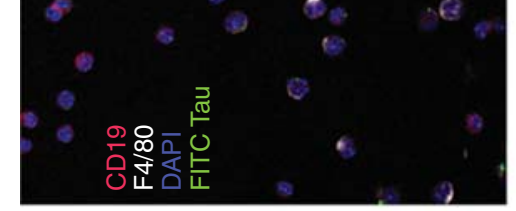

$\varangle$

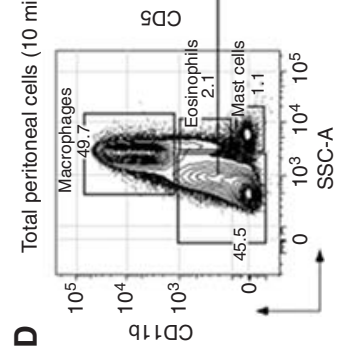


which, because of a mutation in the transmembrane region of IgM, lack expression of all subtypes of B cells (Kitamura et al. 1991). The $\mu \mathrm{MT}$ mice showed equivalent paralytic signs of the disease as wild-type animals, which was consistent with the known importance of $\mathrm{T}$ lymphocytes in disease induction. However, administration of Tau 623-628, or Amylin 28-33 failed to reduce the clinical signs, indicating that the therapeutic activity of the amyloidogenic peptides required the presence of $B$ lymphocytes (Fig. $5 \mathrm{~A}, \mathrm{C}, \mathrm{D})$. Based on the assumption that the B1a cells were critical to the therapeutic activity, the amyloidogenic peptides were tested in IL-10 knockout animals induced with EAE. In these animals as well, the peptides were ineffective (Fig. 5B), establishing that both IL-10 and B lymphocytes are essential for the therapeutic activity of the peptides.

The role of B-1a cells in therapy was tested directly by determining whether adoptive trans- fer into $\mu \mathrm{MT}$ mice restored the immunosuppressive activity of the amyloid fibrils. B-1a cells $\left(\mathrm{CD} 19^{\text {hi }} \mathrm{CD} 5^{+}\right)$were purified by cell sorting, and on day 10 after EAE induction $3.5 \times 10^{5}$ cells were injected into the peritoneum of mice (Kurnellas et al. 2015). The mice were divided into two groups and treated daily with Amylin 28-33 $(10 \mu \mathrm{g})$ or buffer alone. EAE was induced in a third group of $\mu \mathrm{MT}$ mice that did not receive B1a cells but were treated with Amylin 28-33. The paralytic signs of EAE were reduced only in mice that received the transfer of $\mathrm{B}-1 \mathrm{a}$ cells treated daily with the amyloidogenic peptide (Fig. 5E). Interestingly, adoptive transfer of untreated Bla cells was as ineffective as buffer control, establishing that just the presence of B-1a cells was insufficient for therapy. Beneficial immune suppression was seen only when the B-1a cells were activated by the fibrils. These observations were consistent with earlier studies showing regulatory B cells are more potent suppressors of au-
A

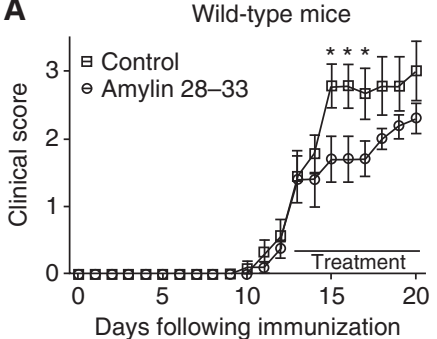

C

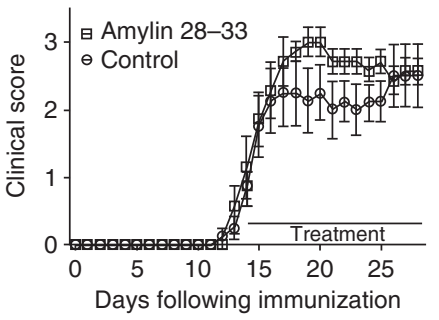

B $\quad \mathrm{LL}-10^{-/-}$mice
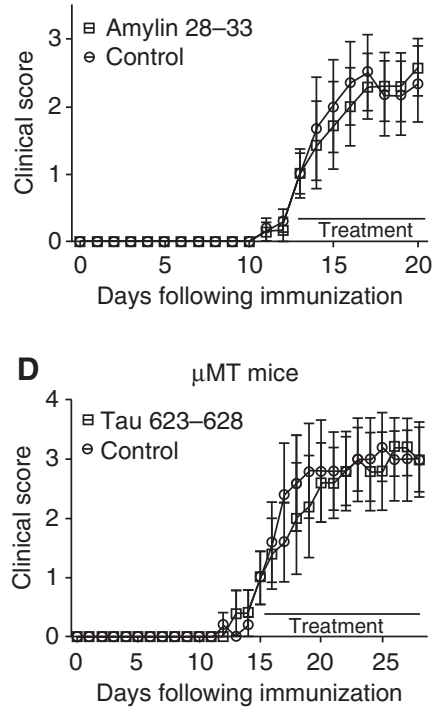

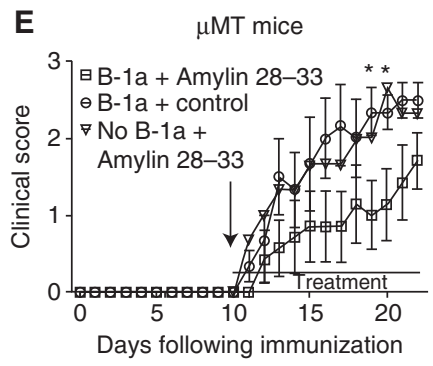

Figure 5. B-1a cells and interleukin (IL)-10 are necessary for therapeutic efficacy of amyloidogenic peptides. Wildtype experimental autoimmune encephalomyelitis (EAE) mice were treated effectively daily, intraperitoneally with $10 \mu \mathrm{g}$ Amylin 28-33 ( $n=10)(A)$. Similar administration of Amylin 28-33 to IL-10-deficient mice $(n=7)$ $(B)$ and $\mu \mathrm{MT}$ mice $(n=10)(C)$ was ineffective. Daily intraperitoneal injections of Tau $623-628$ at onset of symptoms in $\mu$ MT mice $(n=10)$ also was ineffective $(D)$. (E) Adoptive transfer of $3.5 \AA \sim 10^{5}$ B-1a cells into $\mu$ MT mice before the signs of EAE were treated daily intraperitoneally with $10 \mu \mathrm{g}$ Amylin 28-33 or control buffer $(n=6)$. Mice without transfer of cells were treated with $10 \mu \mathrm{g}$ Amylin 28-33. Values in graph represent mean \pm SEM ${ }^{*} P<0.05$ by the Mann-Whitney $U$-test. 
J.B. Rothbard et al.

toimmunity than their inactivated counterparts (Evans et al. 2007; Yoshizaki et al. 2012).

\section{GENE EXPRESSION}

Two separate studies were performed to explore how amyloid fibrils modulated gene expression in specific cell populations. The first explored gene expression in whole blood of mice with EAE (Kurnellas et al. 2014). Mice were treated either with PBS or Tau 623-628 daily, beginning when the animals showed stage two clinical signs. In an attempt to analyze responses before and after reduction of clinical signs, blood was collected before clinical evidence of disease and after clinical signs were minimized, RNA isolated, and the gene expression changes associated with Tau treatment were quantified using a microarray. Two different patterns of gene expression were delineated. The first pattern was characteristic of the reduction of the production of proinflammatory cytokines, IL-6, TNF- $\alpha$, and IFN- $\gamma$ (Kurnellas et al. 2014) with concomitant reduction in the NF- $\kappa \mathrm{B}$ and STAT3 pathways, and down-regulated networks involved in lymphocyte, monocyte, and dendritic cell activation. This was apparent when the expression profile of the RNA isolated from the blood cells at day 10 was compared with that isolated at day 3. The second deconvoluted pathway was neutrophil activation and the induction of type 1 IFN. This arose from the fibrils being endocytosed by neutrophils, subsequent production of neutrophil extracellular traps, which in turn induces plasmacytoid dendritic cells to secrete type 1 IFN (Kurnellas et al. 2014). The two independent pathways stimulated by the fibrils can act in concert to be immunosuppressive in Th1 indications, or in opposition, resulting in inflammation when Th17 $\mathrm{T}$ lymphocytes are predominant. The generation of type 1 IFN could be minimized by the choice of the immunizing peptide. Amylin 28-33 forms amyloid fibrils at a much slower rate than Tau 623-628 and did not induce detectable neutrophil activation and was an effective therapeutic in both Th1- and Th17-induced disease.

The second gene expression study focused on understanding the activation of peritoneal cell MФs and B-1a lymphocytes isolated from mice injected with LPS or amyloid fibrils composed of Tau 623-628 or Amylin 28-33. Because both LPS and the fibrils induce rapid migration from the peritoneal cavity, the timing of the collection of the cells was limited to 30$40 \mathrm{~min}$ postinjection. LPS binding to CD14/ TLR4 on both MФs and B-1a cells induced a well-characterized pattern of gene expression (Kawai and Akira 2010; Rossol et al. 2011), resulting in the induction of a wide spectrum of proinflammatory mediators, including IL-6, TNF- $\alpha$, type 1 IFN, serpins, IL- $1 \alpha$ and IL- $1 \beta$, chemokines CXCL10, CXCL3, MYD88, and $>50$ genes known to be induced by RelA/p65 NF- $\mathrm{B}$ (Bode et al. 2012). In peritoneal MФs, amyloidogenic peptides stimulated a distinctly different pattern of genes from those induced by LPS. The majority of genes preferentially induced by the fibrils corresponded to $M \Phi$ stimulation, cytokine production, oxidative phosphorylation, autophagy, and mitochondrial dysfunction pathways. Oxidative phosphorylation pathway corresponded to a number of mitochondrial genes composing the five complexes involved in mitochondrial electron transport and ATP production, characteristic of amyloid fibril interactions with mitochondria (DuBoff et al. 2013). The induction of oxidative phosphorylation was indicative of differentiation into a regulatory phenotype (Rodriguez-Prados et al. 2010). Analysis of the gene expression patterns in MФs also revealed a profile characteristic of treatment with rapamycin, including inhibition of mTorC1 and the induction of both autophagy and mitophagy, again supporting the differentiation into a regulatory phenotype.

The prominent pattern of induced by the fibrils and LPS in B-1a cells was the pathway of B-cell activation. The amyloidogenic peptides and LPS both stimulated expression of a set of proteins involved in NF- $\mathrm{\kappa B}$ activation, calcium release (stim-1, orai-1, and -3), BcR (CD79, Syk, Lyn, PI3K, Akt, m-Tor, Bcl2A1d, c-src, PTEN, and Vav-1), and CD40 signaling (Traf-2, -4, and -5). In addition to the activation pathways, the amyloid fibrils, and not LPS, induced a unique set of immunosuppressive proteins, such as Band T-lymphocyte attenuator (BTLA), IFN reg- 
ulatory factor 4 (IRF4), CTLA-4, and Siglec G. The fibrils also induced a pattern characteristic of signalosome formation (raftlin, CDC42, CDC42 small effector protein). Quantitative polymerase chain reaction (qPCR) confirmed the patterns seen in the pathway analysis from the chip data, and definitively established that the fibrils significantly reduced gene expression of IL-6, TNF, IL-1 $\beta$, and IFN- $\beta 1$ induced by LPS in the peritoneal MФs, and induced a set of genes associated with immune regulation, BTLA, CTLA-4, Siglec G, and IRF4 in B-1a cells, and CD274 in MФs. PCR experiments also confirmed the induction of Sqstm1 and Sirt1 in $\mathrm{M \Phi s}$, which are associated with autophagy and mitophagy, respectively, and the increased expression of IL-10 in both B-1a and large peritoneal MФs, two of the cell types shown to traffic to lymph nodes. Finally, the expression of IL-10, inhibition of mTorC1 leading to the induction of autophagy and mitophagy, and the stimulation of oxidative phosphorylation in the $M \Phi s$ are consistent with the conversion of these cells to a regulatory phenotype, known to suppress inflammatory responses.

\section{IDENTIFICATION OF THE RECEPTOR(S) FOR AMYLOID FIBRILS AND sHsp}

A central issue that was still poorly understood was the receptor(s) for the fibrils and sHsps on B lymphocytes and peritoneal MФs. Amyloid fibrils have been reported to bind $>20$ different cell surface receptors ranging from TLRs to RAGE and to distinguish between them was believed to be a difficult task. Identification of the receptors required chemical cross-linking of the fibrils to the surfaces of the peritoneal MФs and B-1a lymphocytes. Mass spectral analyses of amyloid fibrils cross-linked to both populations of the peritoneal cells revealed that the fibrils bound nicotinic acetylcholine receptor (nAChR), and $\mathrm{N}$-methyl-D-aspartate receptor (NMDA), subunit $\mathrm{D}$, on $\mathrm{M} \Phi \mathrm{s}, \mathrm{B} 2$, and $\mathrm{B}-1 \mathrm{a}$ cells, but not $\mathrm{T}$ lymphocytes (Rothbard et al. 2018).

Modulation of NMDA glutamate and nAChR signaling can ameliorate EAE, but in diametrically different ways. Therapeutic benefit is observed when the nAChR pathway is stimu-
Stimulation of an Immune Suppressive Pathway

lated (Shi et al. 2009; Hao et al. 2011; Gao et al. 2014; Jiang et al.2016) or when NMDA signaling is inhibited (Olivares et al. 2012). nAChR, and not NMDA, signaling was investigated further because amyloid fibrils and sHsps appeared to be agonists, stimulating pathways of immune suppression strikingly similar to those induced by nicotine (Shi et al. 2009; Hao et al.2011; Gao et al. 2014; Jiang et al. 2016). In addition, $\alpha 7 \mathrm{nAChR}$ is unique among amyloid receptors being integral to an endogenous immune anti-inflammatory pathway involving the vagus nerve (Pavlov and Tracey 2012, 2017). $\alpha 7 n A C h R$ also is expressed as a homopentamer, unlike the NMDA heterotetramer, which has simplified the creation of knockout mice by deleting a single gene. Finally, there are several $\alpha 7 \mathrm{nAChR}$ selective toxins, including $\alpha$-bungarotoxin, which can be used to identify the receptor on the surface of cells.

When $\alpha$-bungarotoxin (selective for $\alpha 1$ in muscle and $\alpha 7-\alpha 10$ nAChR) (Orr-Urtreger et al. 1997; Gotti and Clementi 2004) was used to stain murine peritoneal cells isolated from wild-type C57BL/6 mice, a closely related pattern to that generated by fluorescent analogs of Tau 623-628 and HspB4 was observed. The specificity of $\alpha$-bungarotoxin mirrored that of the fibrils and sHsp, binding both populations of MФs at higher levels than B cells, which was 2-5 times greater than the signal of the T cells, consistent with the three species binding a common receptor. Wang and colleagues $(2000 \mathrm{a}, \mathrm{b})$ previously reported that amyloid $\beta$ bound $\alpha 7 n A C h R$, signaling through Jak2 and Stat3. $\mathrm{nAChR}$ is unique among the $>20$ known receptors for amyloid fibrils, being central in a welldefined physiological mechanism involving the vagus nerve-the inflammatory reflex (Pavlov and Tracey 2017).

Nicotine induces a similar pattern of immune suppression as both sHsps and amyloid fibrils and has been shown to be an effective therapeutic for EAE (Shi et al. 2009; Hao et al. 2011; Gao et al. 2014; Jiang et al. 2016; Shao et al. 2017). In addition to binding $\alpha 7 \mathrm{nAChR}$, nicotine, HspB4, and amyloid fibrils composed of Tau 623-628 all (1) signal through Stat3, (2) inhibit cell surface $\alpha$-bungarotoxin binding, (3) inhibit proinflammatory cytokine secretion, 
J.B. Rothbard et al.

(4) induce autophagy, and (5) are therapeutic in animal models of EAE and require both the expression of $\alpha 7 \mathrm{nAChR}$ and the presence of $\mathrm{B}-1 \mathrm{a}$ lymphocytes to be effective (Rothbard et al. 2018). Collectively, the observations support the conclusion that nicotine, sHsps, and amyloid fibrils are $\alpha 7 \mathrm{nAChR}$ agonists, which induce a common signaling pathway leading to increased oxidative phosphorylation and autophagy (inhibition of apoptosis), inducing regulatory macrophages, which are capable of limiting
T-lymphocyte proliferation and result in the reduction of proinflammatory cytokines (Fig. 6). These findings complement the discoveries that the nervous system and specifically the vagus nerve modulates the immune response via activation of $\alpha 7 \mathrm{nAChR}$ (Pavlov et al. 2007; Pavlov and Tracey 2017). This modulation occurs through the inflammatory reflex in which the vagus nerve interacts with the splenic nerve releasing norepinephrine in the spleen. This norepinephrine binds to $\beta$-adrenergic receptors on

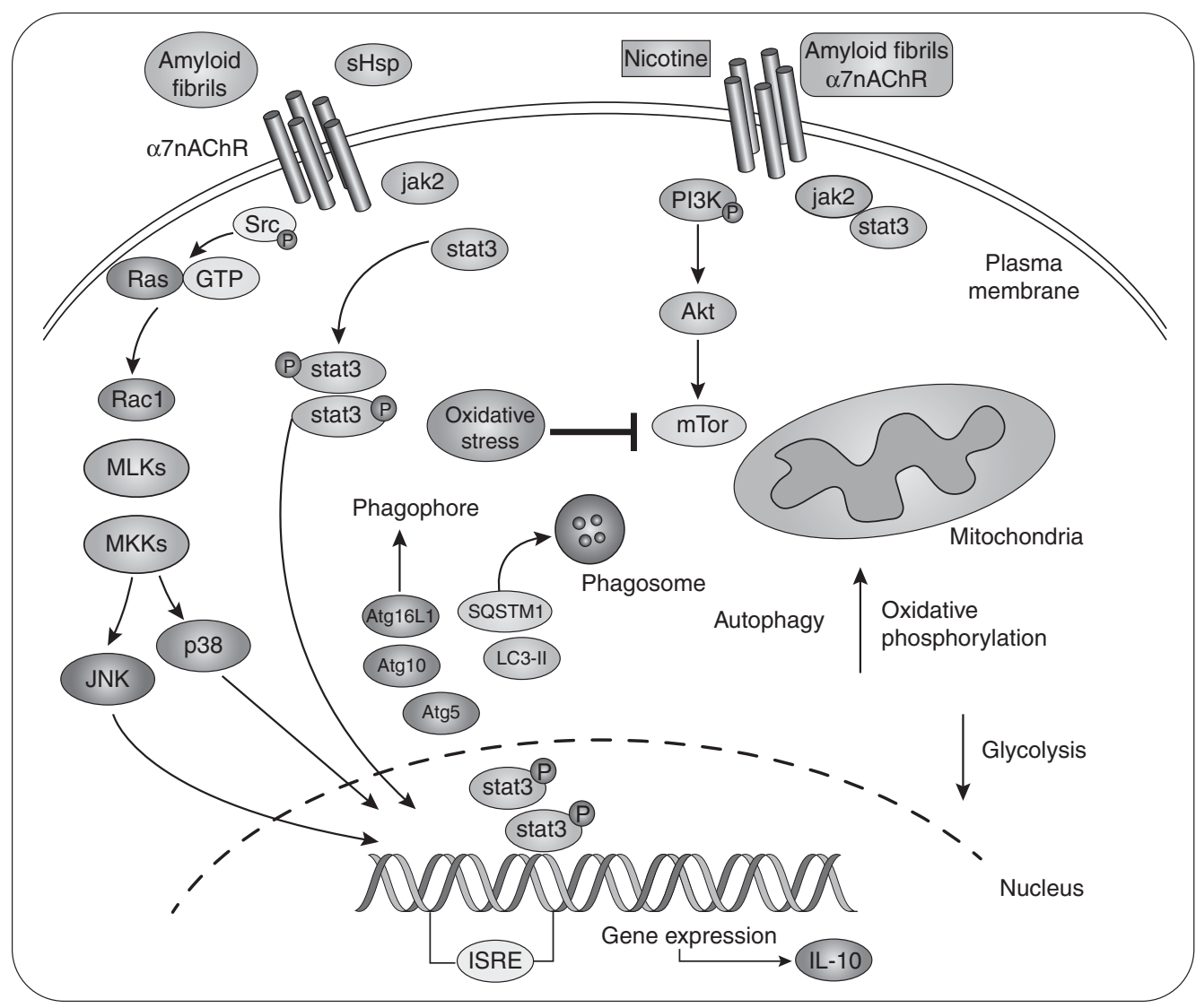

Figure 6. Cartoon representing $\alpha 7$ nicotinic acetylcholine receptor ( $\alpha 7 \mathrm{nAChR})$, signaling pathways induced by the agonists nicotine, small heat shock proteins (sHsps), and amyloid fibrils. Binding of agonists to the receptor on macrophages (MФs) leads to the phosphorylation of Jak2, which in turn leads to phosphorylation of Stat3, which dimerizes, traffics to the nucleus, binds interferon stimulated response element (ISRE), and induces the expression of a set of proteins including interleukin (IL)-10 and DDIT4. The former acts as an autocrine factor, leading to the reduction of nuclear factor $(\mathrm{NF}-\mathrm{\kappa B})$ activation and the production of proinflammatory cytokines, whereas the later protein, along with oxidative stress, inhibits phosphorylation of mammalian target of rapamycin (mTor), which in turn induces autophagy and mitophagy. Agonist binding also stimulates the Map kinase pathway central to growth and proliferation. Finally, activation of $\alpha 7 \mathrm{nAChR}$ has manifold effects on cell metabolism, including the reduction of glycolysis and the enhancement of oxidative phosphorylation. 
T lymphocytes that contain choline acetyltransferase (producing acetylcholine) and activates acetylcholine release. Acetylcholine then binds $\alpha 7 n A C h R$ on MФs and inhibits proinflammatory cytokine release and inflammation (Olofsson et al. 2012). Injection of either sHsps or amyloid fibrils also induces an immune suppressive pathway by directly binding $\alpha 7 \mathrm{nAChR}$. In addition to peritoneal MФs, B lymphocytes, in particular IL-10-producing B-1a cells, also express $\alpha 7 \mathrm{nAChR}$ and are activated by sHsps and amyloid fibrils. Consequently, partial agonists and positive allosteric modulators specific for $\alpha 7 \mathrm{nAChR}$ may systemically modulate this neuroimmune circuit and reduce inflammation in a broad spectrum of diseases.

\section{CONCLUDING REMARKS}

Experimental evidence supports the premise that nicotine, amyloid fibrils, and sHsps are $\alpha 7 \mathrm{nAChR}$ agonists, binding at or near the orthosteric site, and stimulating Stat 3 signaling, inhibition of $\mathrm{mTorCl}$, and the induction of mitophagy and autophagy. The activation of the receptor leads to the reduction of proinflammatory cytokines, including TNF $\alpha$, IL-1 $\beta$, IL- 6 , and IL-18. The clarification of a receptor for the two types of biologics enhances the understanding of their mode of action. The identification also links these findings with the extensive experimental evidence for a potent anti-inflammatory pathway, the inflammatory reflex, in which $\alpha 7 \mathrm{nAChR}$ plays a major mediating role. The inflammatory reflex can be activated by pharmacological activation of $\alpha 7 \mathrm{nAChR}$ or bioelectronic vagus nerve stimulation. Therefore, targeting the $\alpha 7 \mathrm{nAChR}$ by pharmacological or bioelectronics approaches can be considered in the future, strategizing therapeutic approaches for multiple sclerosis, stroke, and other relevant disorders.

\section{ACKNOWLEDGMENTS}

We acknowledge the assistance of our scientific collaborators, Eliver Ghosn, Jeanette Baker, Ahmet Arac, Gary Steinberg, May Han, Suzanne Pangratz-Fuehrer, and Joyce Liao, and our expert technical collaborators, Chris Adams, Ryan
Stimulation of an Immune Suppressive Pathway

Lieb (mass spectrometry), Bianca Gomez (flow cytometry), and Kitty Lee (confocal microscopy) without whom this story could not have been written. This work was supported in part by grants from the National Multiple Sclerosis Society.

\section{REFERENCES}

Arac A, Brownell SE, Rothbard JB, Chen C, Ko RM, Pereira MP, Albers GW, Steinman L, Steinberg GK. 2011. Systemic augmentation of $\alpha \mathrm{B}$-crystallin provides therapeutic benefit twelve hours post-stroke onset via immune modulation. Proc Natl Acad Sci 108: 13287-13292.

Balbirnie M, Grothe R, Eisenberg DS. 2001. An amyloidforming peptide from the yeast prion Sup35 reveals a dehydrated $\beta$-sheet structure for amyloid. Proc Natl Acad Sci 98: 2375-2380.

Bode JG, Ehlting C, Haussinger D. 2012. The macrophage response towards LPS and its control through the p38 (MAPK)-STAT3 axis. Cell Signal 24: 1185-1194.

Chabas D, Baranzini SE, Mitchell D, Bernard CC, Rittling SR, Denhardt DT, Sobel RA, Lock C, Karpuj M, Pedotti R, et al. 2001. The influence of the proinflammatory cytokine, osteopontin, on autoimmune demyelinating disease. Science 294: 1731-1735.

DuBoff B, Feany M, Gotz J. 2013. Why size matters-Balancing mitochondrial dynamics in Alzheimer's disease. Trends Neurosci 36: 325-335.

Evans JG, Chavez-Rueda KA, Eddaoudi A, Meyer-Bahlburg A, Rawlings DJ, Ehrenstein MR, Mauri C. 2007. Novel suppressive function of transitional $2 \mathrm{~B}$ cells in experimental arthritis. J Immunol 178: 7868-7878.

Gao Z, Nissen JC, Ji K, Tsirka SE. 2014. The experimental autoimmune encephalomyelitis disease course is modulated by nicotine and other cigarette smoke components. PLOS ONE 9: e107979.

Goldschmidt L, Teng PK, Riek R, Eisenberg D. 2010. Identifying the amylome, proteins capable of forming amyloid-like fibrils. Proc Natl Acad Sci 107: 3487-3492.

Gotti C, Clementi F. 2004. Neuronal nicotinic receptors: From structure to pathology. Prog Neurobiol 74: 363-396.

Han MH, Hwang SI, Roy DB, Lundgren DH, Price JV, Ousman SS, Fernald GH, Gerlitz B, Robinson WH, Baranzini SE, et al. 2008. Proteomic analysis of active multiple sclerosis lesions reveals therapeutic targets. Nature 451: 1076-1081.

Hao J, Simard AR, Turner GH, Wu J, Whiteaker P, Lukas RJ, Shi FD. 2011. Attenuation of CNS inflammatory responses by nicotine involves $\alpha 7$ and non- $\alpha 7$ nicotinic receptors. Exp Neurol 227: 110-119.

Haslbeck M, Braun N, Stromer T, Richter B, Model N, Weinkauf S, Buchner J. 2004. Hsp42 is the general small heat shock protein in the cytosol of Saccharomyces cerevisiae. EMBO J 23: 638-649.

Haslbeck M, Franzmann T, Weinfurtner D, Buchner J. 2005. Some like it hot: The structure and function of small heatshock proteins. Nat Struct Mol Biol 12: 842-846. 
J.B. Rothbard et al.

Hochberg GKA, Shepherd DA, Marklund EG, Santhanagoplan I, Degiacomi MT, Laganowsky A, Allison TM, Basha E, Marty MT, Galpin MR, et al. 2018. Structural principles that enable oligomeric small heat-shock protein paralogs to evolve distinct functions. Science 359: 930-935.

Jiang W, St-Pierre S, Roy P, Morley BJ, Hao J, Simard AR. 2016. Infiltration of CCR $2^{+} \mathrm{Ly} 6 \mathrm{C}^{\text {high }}$ proinflammatory monocytes and neutrophils into the central nervous system is modulated by nicotinic acetylcholine receptors in a model of multiple sclerosis. J Immunol 196: 2095-2108.

Kamradt MC, Chen F, Cryns VL. 2001. The small heat shock protein $\alpha \mathrm{B}$-crystallin negatively regulates cytochrome cand caspase-8-dependent activation of caspase- 3 by inhibiting its autoproteolytic maturation. J Biol Chem 276: 16059-16063.

Kamradt MC, Lu M, Werner ME, Kwan T, Chen F, Strohecker A, Oshita S, Wilkinson JC, Yu C, Oliver PG, et al 2005. The small heat shock protein $\alpha \mathrm{B}$-crystallin is a novel inhibitor of TRAIL-induced apoptosis that suppresses the activation of caspase-3. J Biol Chem 280: 11059-11066.

Kappe G, Leunissen JA, de Jong WW. 2002. Evolution and diversity of prokaryotic small heat shock proteins. Prog Mol Subcell Biol 28: 1-17.

Kappe G, Franck E, Verschuure P, Boelens WC, Leunissen JA, de Jong WW. 2003. The human genome encodes 10 $\alpha$-crystallin-related small heat shock proteins: HspB1-10. Cell Stress Chaperones 8: 53-61.

Kawai T, Akira S. 2010. The role of pattern-recognition receptors in innate immunity: Update on Toll-like receptors. Nat Immunol 11: 373-384.

Kennaway CK, Benesch JL, Gohlke U, Wang L, Robinson CV, Orlova EV, Saibil HR, Keep NH. 2005. Dodecameric structure of the small heat shock protein Acrl from $M y$ cobacterium tuberculosis. J Biol Chem 280: 33419-33425.

Kim KK, Kim R, Kim SH. 1998a. Crystal structure of a smal heat-shock protein. Nature 394: 595-599.

Kim R, Kim KK, Yokota H, Kim SH. 1998b. Small heat shock protein of Methanococcus jannaschii, a hyperthermophile. Proc Natl Acad Sci 95: 9129-9133.

Kitamura D, Roes J, Kuhn R, Rajewsky K. 1991. A B celldeficient mouse by targeted disruption of the membrane exon of the immunoglobulin mu chain gene. Nature 350: 423-426.

Kurnellas MP, Brownell SE, Su L, Malkovskiy AV, Rajadas J, Dolganov G, Chopra S, Schoolnik GK, Sobel RA, Webster J, et al. 2012. Chaperone activity of small heat shock proteins underlies therapeutic efficacy in experimental autoimmune encephalomyelitis. J Biol Chem 287: 36423 36434.

Kurnellas MP, Adams CM, Sobel RA, Steinman L, Rothbard JB. 2013. Amyloid fibrils composed of hexameric peptides attenuate neuroinflammation. Sci Transl Med 5: 179ra142.

Kurnellas MP, Schartner JM, Fathman CG, Jagger A, Steinman L, Rothbard JB. 2014. Mechanisms of action of therapeutic amyloidogenic hexapeptides in amelioration of inflammatory brain disease. J Exp Med 211: 1847-1856.

Kurnellas MP, Ghosn EE, Schartner JM, Baker J, Rothbard JJ, Negrin RS, Herzenberg LA, Fathman CG, Steinman L, Rothbard JB. 2015. Amyloid fibrils activate B-1a lymphocytes to ameliorate inflammatory brain disease. Proc Natl Acad Sci 112: 15016-15023.
Laganowsky A, Benesch JL, Landau M, Ding L, Sawaya MR, Cascio D, Huang Q, Robinson CV, Horwitz J, Eisenberg D. 2010. Crystal structures of truncated $\alpha \mathrm{A}$ and $\alpha \mathrm{B}$ crystallins reveal structural mechanisms of polydispersity important for eye lens function. Protein Sci 19: 1031-1043.

Laganowsky A, Liu C, Sawaya MR, Whitelegge JP, Park J, Zhao M, Pensalfini A, Soriaga AB, Landau M, Teng PK, et al. 2012. Atomic view of a toxic amyloid small oligomer. Science 335: 1228-1231.

Liu B, Bhat M, Nagaraj RH. 2004. $\alpha$ B-crystallin inhibits glucose-induced apoptosis in vascular endothelial cells. Biochem Biophys Res Commun 321: 254-258.

Liu S, Li J, Tao Y, Xiao X. 2007. Small heat shock protein $\alpha B$ crystallin binds to p53 to sequester its translocation to mitochondria during hydrogen peroxide-induced apoptosis. Biochem Biophys Res Commun 354: 109-114.

Mao YW, Liu JP, Xiang H, Li DW. 2004. Human $\alpha$ A- and $\alpha \mathrm{B}$-crystallins bind to $\mathrm{Bax}$ and $\mathrm{Bcl}-\mathrm{X}(\mathrm{S})$ to sequester their translocation during staurosporine-induced apoptosis. Cell Death Differ 11: 512-526.

Narberhaus F. 2002. $\alpha$-crystallin-type heat shock proteins Socializing minichaperones in the context of a multichaperone network. Microbiol Mol Biol Rev 66: 64-93.

Nelson R, Sawaya MR, Balbirnie M, Madsen AO, Riekel C, Grothe R, Eisenberg D. 2005. Structure of the cross- $\beta$ spine of amyloid-like fibrils. Nature 435: 773-778.

O'Garra A, Howard M. 1992. IL-10 production by CD5 B cells. Ann NY Acad Sci 651: 182-199.

O'Garra A, Chang R, Go N, Hastings R, Haughton G, Howard M. 1992. Ly-1 B (B-1) cells are the main source of B cell-derived interleukin 10. Eur J Immunol 22: 711-717.

Olivares D, Deshpande VK, Shi Y, Lahiri DK, Greig NH, Rogers JT, Huang X. 2012. N-methyl-D-aspartate (NMDA) receptor antagonists and memantine treatment for Alzheimer's disease, vascular dementia and Parkinson's disease. Curr Alzheimer Res 9: 746-758.

Olofsson PS, Rosas-Ballina M, Levine YA, Tracey KJ. 2012. Rethinking inflammation: Neural circuits in the regulation of immunity. Immunol Rev 248: 188-204.

Orr-Urtreger A, Goldner FM, Saeki M, Lorenzo I, Goldberg L, De Biasi M, Dani JA, Patrick JW, Beaudet AL. 1997. Mice deficient in the $\alpha 7$ neuronal nicotinic acetylcholine receptor lack $\alpha$-bungarotoxin binding sites and hippocampal fast nicotinic currents. J Neurosci 17: 9165-9171.

Ousman SS, Tomooka BH, van Noort JM, Wawrousek EF, O'Conner K, Hafler DA, Sobel RA, Robinson WH, Steinman L. 2007. Protective and therapeutic role for $\alpha B$-crystallin in autoimmune demyelination. Nature 448: 474479.

Pangratz-Fuehrer S, Kaur K, Ousman SS, Steinman L, Liao YJ. 2011. Functional rescue of experimental ischemic optic neuropathy with $\alpha \mathrm{B}$-crystallin. Eye (Lond) 25: 809817.

Pasta SY, Raman B, Ramakrishna T, Rao Ch M. 2004. The IXI/V motif in the C-terminal extension of $\alpha$-crystallins: Alternative interactions and oligomeric assemblies. $\mathrm{Mol}$ Vis 10: 655-662.

Pavlov VA, Tracey KJ. 2012. The vagus nerve and the inflammatory reflex-Linking immunity and metabolism. Nat Rev Endocrinol 8: 743-754. 
Pavlov VA, Tracey KJ. 2017. Neural regulation of immunity: Molecular mechanisms and clinical translation. Nat Neurosci 20: 156-166.

Pavlov VA, Ochani M, Yang LH, Gallowitsch-Puerta M, Ochani K, Lin X, Levi J, Parrish WR, Rosas-Ballina M, Czura CJ, et al. 2007. Selective $\alpha 7$-nicotinic acetylcholine receptor agonist GTS-21 improves survival in murine endotoxemia and severe sepsis. Crit Care Med 35: 11391144

Rodriguez-Prados JC, Traves PG, Cuenca J, Rico D, Aragones J, Martin-Sanz P, Cascante M, Bosca L. 2010. Substrate fate in activated macrophages: A comparison between innate, classic, and alternative activation. J Immunol 185: 605-614.

Rossol M, Heine H, Meusch U, Quandt D, Klein C, Sweet MJ, Hauschildt S. 2011. LPS-induced cytokine production in human monocytes and macrophages. Crit Rev Immunol 31: 379-446.

Rothbard JB, Rothbard JJ, Soares L, Fathman CG, Steinman L. 2018. Identification of a common immune regulatory pathway induced by small heat shock proteins, amyloid fibrils, and nicotine. Proc Natl Acad Sci 115: 7081-7086.

Sawaya MR, Sambashivan S, Nelson R, Ivanova MI, Sievers SA, Apostol MI, Thompson MJ, Balbirnie M, Wiltzius JJ, McFarlane HT, et al. 2007. Atomic structures of amyloid cross- $\beta$ spines reveal varied steric zippers. Nature 447: 453-457.

Shao BZ, Ke P, Xu ZQ, Wei W, Cheng MH, Han BZ, Chen XW, Su DF, Liu C. 2017. Autophagy plays an importan role in anti-inflammatory mechanisms stimulated by $\alpha 7$ nicotinic acetylcholine receptor. Front Immunol 8: 553.

Shi FD, Piao WH, Kuo YP, Campagnolo DI, Vollmer TL, Lukas RJ. 2009. Nicotinic attenuation of central nervous
Stimulation of an Immune Suppressive Pathway

system inflammation and autoimmunity. J Immunol 182: 1730-1739.

Tanaka N, Tanaka R, Tokuhara M, Kunugi S, Lee YF, Hamada D. 2008. Amyloid fibril formation and chaperone-like activity of peptides from $\alpha \mathrm{A}$-crystallin. Biochemistry 47: 2961-2967.

Thompson MJ, Sievers SA, Karanicolas J, Ivanova MI, Baker D, Eisenberg D. 2006. The 3D profile method for identifying fibril-forming segments of proteins. Proc Natl Acad Sci 103: 4074-4078.

van Montfort RL, Basha E, Friedrich KL, Slingsby C, Vierling E. 2001. Crystal structure and assembly of a eukaryotic small heat shock protein. Nat Struct Biol 8: 1025-1030.

Velotta JB, Kimura N, Chang SH, Chung J, Itoh S, Rothbard J, Yang PC, Steinman L, Robbins RC, Fischbein MP. 2011. $\alpha \mathrm{B}$-crystallin improves murine cardiac function and attenuates apoptosis in human endothelial cells exposed to ischemia-reperfusion. Ann Thorac Surg 91: 1907-1913.

Wang HY, Lee DH, D’Andrea MR, Peterson PA, Shank RP, Reitz AB. 2000a. $\beta$-Amyloid(1-42) binds to $\alpha 7$ nicotinic acetylcholine receptor with high affinity. Implications for Alzheimer's disease pathology. J Biol Chem 275: 56265632.

Wang HY, Lee DH, Davis CB, Shank RP. 2000b. Amyloid peptide $A \beta(1-42)$ binds selectively and with picomolar affinity to $\alpha 7$ nicotinic acetylcholine receptors. J Neurochem 75: 1155-1161.

Yoshizaki A, Miyagaki T, DiLillo DJ, Matsushita T, Horikawa M, Kountikov EI, Spolski R, Poe JC, Leonard WJ, Tedder TF. 2012. Regulatory B cells control T-cell autoimmunity through IL-21-dependent cognate interactions. Nature 491: 264-268. 


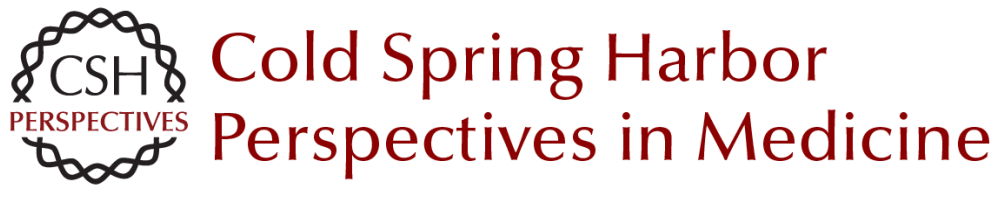

\section{Small Heat Shock Proteins, Amyloid Fibrils, and Nicotine Stimulate a Common Immune Suppressive Pathway with Implications for Future Therapies}

Jonathan B. Rothbard, Michael P. Kurnellas, Shalina S. Ousman, Sara Brownell, Jesse J. Rothbard and Lawrence Steinman

Cold Spring Harb Perspect Med 2019; doi: 10.1101/cshperspect.a034223 originally published online September 24, 2018

\section{Subject Collection Bioelectronic Medicine}

Neural Control of Inflammation: Bioelectronic Medicine in Treatment of Chronic Inflammatory Disease

Michael Eberhardson, Laura Tarnawski, Monica Centa, et al.

Noninvasive Neuromodulation of Peripheral Nerve Pathways Using Ultrasound and Its Current Therapeutic Implications

Christopher Puleo and Victoria Cotero

Enteric Neuromodulation for the Gut and Beyond Yogi A. Patel and Pankaj J. Pasricha

Optogenetic Control of the Peripheral Nervous System

Rui B. Chang

Closed-Loop Neuromodulation in Physiological and Translational Research Stavros Zanos

Electrical Impedance Methods in Neuromuscular Assessment: An Overview Seward B. Rutkove and Benjamin Sanchez

Optogenetic Medicine: Synthetic Therapeutic Solutions Precision-Guided by Light Haifeng $\mathrm{Ye}$ and Martin Fussenegger

Technobiology's Enabler: The Magnetoelectric Nanoparticle

Sakhrat Khizroev
Bioelectronic Medicine: From Preclinical Studies on the Inflammatory Reflex to New Approaches in Disease Diagnosis and Treatment

Valentin A. Pavlov, Sangeeta S. Chavan and Kevin J. Tracey

Vagus Nerve Stimulation and the Cardiovascular System

Michael J. Capilupi, Samantha M. Kerath and Lance B. Becker

Harnessing the Inflammatory Reflex for the

Treatment of Inflammation-Mediated Diseases Yaakov A. Levine, Michael Faltys and David Chernoff

Recording and Decoding of Vagal Neural Signals Related to Changes in Physiological Parameters and Biomarkers of Disease Theodoros $P$. Zanos

Restoring Movement in Paralysis with a

Bioelectronic Neural Bypass Approach: Current

State and Future Directions Chad E. Bouton

Bioelectronic Medicine--Ethical Concerns Samuel Packer, Nicholas Mercado and Anita Haridat

Use of Bioelectronics in the Gastrointestinal Tract Larry Miller, Aydin Farajidavar and Anil Vegesna

Vagus Nerve Stimulation at the Interface of BrainGut Interactions

Bruno Bonaz, Valérie Sinniger and Sonia Pellissier

For additional articles in this collection, see http://perspectivesinmedicine.cshlp.org/cgi/collection/ 